https://helda.helsinki.fi

\title{
Associations of changes in diet and leisure-time physical activity with employer's direct cost of short-term sickness absence
}

\section{Salmela, Jatta Helena}

2020

Salmela , J H , Lahti , J , Mauramo , E , Pietiläinen , O , Rahkonen , O \& Kanerva , N 2020 , ' Associations of changes in diet and leisure-time physical activity with employer's direct cost of short-term sickness absence ' , European Journal of Sport Science , vol. 20 , no. 2 , pp. 240-248 . https://doi.org/10.1080/17461391.2019.1647289

http://hdl.handle.net/10138/318189

https://doi.org/10.1080/17461391.2019.1647289

acceptedVersion

Downloaded from Helda, University of Helsinki institutional repository.

This is an electronic reprint of the original article.

This reprint may differ from the original in pagination and typographic detail.

Please cite the original version. 


\section{Associations of changes in diet and leisure-time physical activity with employer's direct cost of short-term sickness absence}

Corresponding author: Jatta Salmela (MSc)

Department of Public Health

University of Helsinki

PO Box 20 (Tukholmankatu 8 B)

00014 University of Helsinki

Email: jatta.salmela@helsinki.fi

Phone: +358407438750 ;

Jouni Lahti, PhD, jouni.mm.lahti@helsinki.fi, the University of Helsinki; Elina Mauramo, PhD, elina.mauramo@helsinki.fi, the University of Helsinki; Olli Pietiläinen, MSc, olli.k.pietilainen@helsinki.fi, the University of Helsinki, Ossi Rahkonen, PhD, ossi.rahkonen@helsinki.fi; Noora Kanerva, PhD, noora.kanerva@helsinki.fi, the University of Helsinki

\section{Author contributions}

NK and JL contributed to the design of the study, assisted with data analysis and participated in critical revision of the manuscript. JS performed the data analyses and drafted the manuscript. EM, OP and OR were involved in interpreting results and critically reviewed the manuscript. All authors read and approved the final manuscript as submitted. 
1 Associations of changes in diet and leisure-time physical activity with employer's direct

2 cost of short-term sickness absence

3

4

5

6

7

8

9

10

11

12

13

14

15

16

17

18

19

20

21

22

23

\section{Abstract}

Several unhealthy lifestyles are associated with increased sickness absence (SA). This study examined the associations of changes in diet and leisure-time physical activity (LTPA) with employer's direct cost of subsequent short-term ( $<10$ working days) SA. The survey data from phases 1 (2000-02) and 2 (2007) of the Helsinki Health Study (HHS), a longitudinal cohort study of initially 40-60-year-old employees of the City of Helsinki, Finland, were linked with SA register data. Final data consisted of 4157 employees. Dietary habits were inquired with a short food frequency questionnaire. Consumption of fruits $(\mathrm{F})$ and vegetables $(\mathrm{V})$ was used to indicate healthiness of diet. LTPA was measured with a series of questions on the intensity and the amount of LTPA. Data on shortterm SA and salaries (2008-12) were received from the employers' registers. A two-part model was used to analyse the associations. Those who improved their $\mathrm{F} \& \mathrm{~V}$ consumption from non-daily to daily and persevered physically active got $620 €(95 \%$ CI $-1194,-47)$ lower cost than those remaining non-daily F\&V consumers and physically inactive. When examining LTPA only, those who persevered physically active or improved from moderately active to active got $19 \%$ less cost for the employer than those remaining inactive. Dietary changes were not independently associated with the cost. Improving employees' diet and LTPA may reduce employer's direct cost of SA. Although the associations of diet with SA cost were not statistically significant, improvements in diet may contribute to the beneficial associations of LTPA and employer's cost of SA.

\section{Keywords}

Cost, Diet, Employees, Leisure-time Physical Activity, Sickness Absence, Worksites 


\section{Introduction}

Unhealthy diet and physical inactivity contribute to chronic diseases, thus causing economic burden in societies (Candari, Cylus, \& Nolte, 2017). The estimated annual healthcare cost range for unhealthy diets is $3-148 €$ and for physical activity (PA) 3-181 € per capita (Candari et al., 2017). On average, unhealthy diet and physical inactivity are attributable to approximately $2 \%$ of the total healthcare costs (Proper \& van Mechelen, 2008). In addition, unhealthy lifestyles and lifestyle-related common diseases are associated with weakened work ability and productivity, and increased sickness absence (SA) (van den Berg, Burdof, \& Robroek, 2017; Leijten et al., 2014; Robroek, van den Berg, Plat, \& Burdof, 2011), which lead to additional cost also for the employers. Our previous study (Kanerva, Pietiläinen, Lallukka, Rahkonen, \& Lahti, 2018) found that several unhealthy lifestyles may increase the direct cost of short-term SA to the employer by up to $30 \%$.

Previous studies have shown that physical inactivity is associated with increased SA (Kerner, Rakovac, \& Lazinica, 2017) and their cost (Tolonen, Rahkonen, \& Lahti, 2017), but the role of diet in SA is still unclear. Some diet-related factors, including obesity, high blood glucose and blood pressure, have been shown to increase SA cost (Kowlessar, Goetzel, Carls, Tabrizi, \& Guindon, 2011). There may also be joint associations of diet and PA with SA as diet and PA have both separately and together several positive effects on health (G.A. Kelley \& Kelley, 2012; Walker, O’Dea, Gomez, Girgis, \& Colagiuri, 2010; Davies, Batehup, \& Thomas, 2011). Improving employees' diet and PA may prevent SA cost, but studies on the effects of lifestyle changes on SA are lacking. The estimated cost of SA in the European countries is $2.5 \%$ of GDP (Edwards \& Greasley, 2010). 
In general, costs are divided into direct, including salary and replacement cost, and indirect cost, including decreased production and management cost. Data on short-term SA are not often available due to lack of comprehensive registers, which is one reason for the lacking evidence. Short-term SA have been shown to predict subsequent SA due to ill-health they reflect (Hultin, Lindholm, Malfert, \& Möller, 2012). Thus, early recognition of the risk factors beyond shortterm SA may have significant, far-reaching health and economic consequences.

This study aimed to investigate the associations of changes in diet and leisure-time physical activity (LTPA) with employer's direct cost of subsequent short-term (<10 working days) SA. Employer's comprehensive register of SA data and individual salaries were used to estimate the real cost of SA among midlife and ageing employees of the City of Helsinki.

\section{Materials and Methods}

\section{Study Design, Setting and Participants}

The Helsinki Health Study (HHS) invited all 40-60-year-old employees of the City of Helsinki, Finland, to participate the survey of 2000-02 (phase 1) (Lahelma et al., 2013). The sample consisted of 13346 employees, with 67\% responding ( $n=8960)$. Phase 1 respondents received a similar follow-up questionnaire in phase $2(2007)$, with $83 \%$ responding $(n=7332)$. Data from 2000 to 2007 were used to examine the changes in diet and LTPA. The survey data were linked with employer's personnel registers providing the information on short-term SA, salaries and employment time (2008-12), by using unique personal identification number given to each Finnish citizen. Those not consenting to linkage $(n=1449)$ and those no longer employed by the City of Helsinki ( $n=1726)$ were excluded. The final data consisted of 4157 employees. The HHS protocol was approved by the ethics committees of the Department of Public Health, University of Helsinki and the health authorities of the City of Helsinki. 
74

75

\section{Measures}

\section{Cost of Sickness Absence}

Individual annual gross salary data from the employers' personnel register were used to calculate the cost of short-term SA ( $<10$ working days). Salaries were first converted to 2012 earnings level using local government wage and salary indices (Statistics Finland, 2018). Then, participant's average daily earnings for each follow-up year were calculated: the individual annual salary was divided by participant's employment months, and then divided by 21 . The number of annual short-term SA days was multiplied with the daily salary of the particular year. For total SA cost per individual, annual costs between 2008 and 2012 were summed.

\section{Diet}

Food frequency questionnaire (FFQ) included 20 questions about different foods consumed during the past four weeks. There were seven frequency alternatives to choose from, varying from "not at all during the past 4 weeks" to "twice a day or more". Participants' fruit and vegetable $(\mathrm{F} \& \mathrm{~V})$ consumption was classified into three groups based on the Finnish nutrition recommendations (The National Nutrition Council of Finland, 2014): consuming neither F nor $\mathrm{V}$ daily, consuming either $\mathrm{F}$ or $\mathrm{V}$ daily and consuming both $\mathrm{F}$ and $\mathrm{V}$ daily. F\&V consumption variables from phases 1 and 2 were combined into a 9-group variable reflecting change. Dark bread consumption was dichotomised into non-daily (5-6 times a week or less) and daily (once a day or more) and thus, the change variable consisted of four groups. Meat consumption was dichotomised into participants consuming meat or meat products moderately $(2-4$ times a week or less) and frequently (5-6 times a week or more). The combined change variable in meat consumption consisted of four groups. 
In addition to FFQ, there were two questions about the fat products used as bread spread (6 alternatives) and in cooking (10 alternatives). Each alternative was categorised either into vegetable-oil-based or animal-based fats. Participants choosing vegetable oil-based fats both for spread and cooking formed a group of "vegetable oils", participants choosing animal-based fat either for spread or cooking formed a group of "mixed fats" and participants choosing animal-based fat both for spread and cooking formed a group of "animal fats". Consequently, the change variable consisted of nine groups. If the responder had missing data or more than one chosen alternative concerning a food habit in question ( $\mathrm{F} \& \mathrm{~V} n=71$, dark bread $n=56$, meat $n=63$ and fat $n=441$ ), the answer was marked as zero, corresponding to not meeting the recommendations.

\section{Physical Activity}

Leisure-time physical activity (LTPA) was measured with a question on the frequency and intensity of exercise in leisure-time or commuting during the past 12 months. The intensity of exercise included four grades: walking, brisk walking, jogging and running or equivalent activities. In addition, average weekly hours in each intensity grade were asked with five alternatives from "not at all" to "four hours or more". From these questions, metabolic equivalent (MET) index was constructed. The total weekly MET-hours were calculated by multiplying the estimated MET value of each intensity grade (Kujala, Kaprio, Sarna, \& Koskenvuo, 1998) by the time used and combining the MET-hours of four intensity grades (Lahti, Lahelma, \& Rahkonen, 2012). Then, respondents were classified into three groups both in phases 1 and 2: inactive $\left(<14\right.$ MET-hours week $\left.{ }^{-1}\right)$, moderately active $(\geq 14$ MET-hours week ${ }^{1}$ including the two lowest intensity grades) and active $\left(\geq 14\right.$ MET-hours week ${ }^{-1}$ the two highest intensity grades) (Lahti et al., 2012). Consequently, the change variable consisted of nine 
122 groups. If the responder had missing data $(n=54)$, the response was marked as zero, 123 corresponding to the lowest activity level.

Joint - Diet and Physical Activity

126 The joint variable of diet and PA consisted of changes in F\&V consumption and LTPA. F\&V

127 consumption was chosen to the joint variable to indicate the healthiness of participants' diet.

128 Changes in dark bread and meat consumption and in quality of fat, and their associations with employer's direct cost of SA were also investigated, but their independent associations were more inconsistent than the associations of changes in $\mathrm{F} \& \mathrm{~V}$ consumption and cost. Instead of 9group change variables, in order to get a reasonable number of groups to the joint variable, we used 4-group change variables for both $\mathrm{F} \& \mathrm{~V}$ consumption and LTPA. In F\&V consumption, this means that only those who consumed both $F \& V$ daily were included in the group of daily consumers, and the rest into the non-daily consumers. LTPA was estimated as described above, though combining the groups of moderately active and active. Consequently, the joint variable consisted of 16 groups.

\section{Covariates}

139 To control for confounding, information on participants' age, gender, work years, prior SA days

140 during the year before 5-year SA follow-up period, occupational position, marital status, 141 smoking, binge drinking, sleeping hours and occupational physical workload were used. Data 142 on participants' work years, prior SA days and occupational position were received from the 143 employers' registers whereas other covariates were derived from the phase 2 questionnaires. 144 Occupational position included four classes: professionals or managers, semi-professionals, 145 routine non-manuals and manual workers. Marital status was classified into those in 146 relationship and those not in relationship. Smoking status was classified into non-smokers and 
147 current smokers. Alcohol use was classified into no binge drinking (those answering "never")

148 and binge drinking (all others). Sleeping hours were classified into $7-8$ hours and $<7$ or $>8$

149 hours a day. Occupational physical workload was classified into heavy or light according to the

150 response to a question on how physically strenuous the respondent found their work.

152 Statistical Analysis

153 Descriptive analyses by different background, dietary and LTPA groups were performed among 154 all participants and separately among those who had SA (Tables 1 and 2). To estimate participants' short-term SA and their cost, mean and standard deviation (SD) were calculated.

156 A two-part model was used to analyse the associations of changes in diet and LTPA with the 157 cost. Each dietary and LTPA variable was investigated separately from each other. The 158 probability of having short-term SA among all participants was analysed first using generalised 159 linear model with binomial regression. Then, the associations of changes in diet and LTPA with 160 the SA cost were analysed among employees who had short-term SA during 2008-12, using 161 generalised linear model with gamma distribution and log-link function. To control for 162 confounding, both analyses were first adjusted for age, gender and work years (Model 1) and 163 then additionally, for other covariates (Model 2). Finally, marginal effects were evaluated at 164 covariate means to estimate the cost in euros. As a sensitivity analysis, all statistical tests were 165 redone by excluding those with missing information in F\&V or LTPA variables. The results of 166 the sensitivity analysis did not differ from the main results. Also, the associations of changes in 167 diet and LTPA with short-term SA days were examined, and the results were similar with the 168 results concerning SA cost. All analyses were performed using IBM SPSS Statistics version 22 169 and STATA version 15. 


\section{Results}

Of all participants, $84 \%(n=3510)$ had at least one short-term SA spell during the 5-year followup (Table 1). Participants who had unhealthier lifestyles in terms of smoking, alcohol use and sleeping had more SA days and got higher cost for the employer than those with healthier lifestyles. Table 2 shows the descriptive statistics of short-term SA and their direct cost in dietary and LTPA change variables among all participants and among those who had shortterm SA during the follow-up (see Table S1 for fat, bread and meat variables). Concerning change in $\mathrm{F} \& \mathrm{~V}$ consumption, the most SA days and the highest cost were among those who did not consume F\&V daily over the 5-year follow-up. Concerning change in LTPA, the most SA days and the highest cost were among those who decreased their LTPA from moderately active to inactive (Table 2).

[Table 1 and 2 near here].

Cost estimates for the contribution of changes in diet and LTPA on employer's direct cost of short-term SA, based on two-part model are shown in Table 3. Supplementary table 2, with the complete results of the two-part model, shows that changes in F\&V consumption and LTPA were not associated with having short-term SA among all participants (Model 2, logistic regression). In dietary changes, statistically significant associations with SA cost were found only for change of F\&V consumption, when adjusting for gender, age and work years (Table 3, Model 1), whereas changes in fat quality, dark bread and meat consumption were not statistically significantly associated with the cost (see Table S3). In general, increasing F\&V consumption or persevering frequent $\mathrm{F} \& \mathrm{~V}$ consumption got lower cost of short-term $\mathrm{SA}$ compared to those who did not report daily F\&V consumption over the follow-up (Table 3, Model 1). After adjusting for more covariates (Table 3, Model 2), however, no statistically 
196 significant results were found. Concerning change in LTPA, persevering physically active got

$197898 €(95 \%$ CI $-1331,-464, p<0.001)$ and improving from moderately active to active got 857

$198 €(95 \% \mathrm{CI}-1345,-369, p=0.001)$ lower cost compared to those who persevered inactive

199 (reference group) (Table 3, Model 1). The mean cost among reference group was $3609 €(95 \%$

200 CI 3226, 3992). The results attenuated but remained statistically significant after adjusting for

201 more covariates (Table 3, Model 2).

202

203 [Table 3 near here].

204

205 The joint associations of changes in diet and LTPA with the SA cost have been illustrated in

206 Figure 1. The figure shows the estimated cost in different joint groups compared to those who

207 remained non-daily F\&V consumers and physically inactive (reference group) over the follow-

208 up. Changing from non-daily to daily F\&V consumer and persevering physically active was

209 associated with $620 €(95 \%$ CI $-1194,-47, p=0.034)$ lower cost compared to the reference

210 group (mean cost $3479 €, 95 \%$ CI 2989, 3969). Furthermore, those persevering in daily F\&V

211 consumption and physically active got $507 €(95 \% \mathrm{CI}=-1036,21, p=0.060)$ lower cost than

212 the reference group. The highest cost for the employer got those who decreased their F\&V

213 consumption from daily to non-daily and remained inactive, but the association was not

214 statistically significant.

215

216 [Figure 1 near here].

\section{Discussion}

219 This study showed that maintaining a healthy diet and a physically active lifestyle as well as 220 improvements in these may decrease employer's direct cost of short-term ( $<10$ working days) 
221 SA. F\&V consumption was used to indicate the healthiness of participant's diet in general.

222 Employees who increased their F\&V consumption from non-daily to daily and persevered 223 physically active got $620 €$ less cost than those remaining non-daily F\&V consumers and 224 physically inactive. When examining only LTPA, the lowest cost for the employer got those 225 who either persevered physically active or increased their activity level from moderate to active, 226 both with $19 \%$ reduction of cost compared to those remaining inactive. Also, in dietary changes, 227 there was a tendency that those who increased their F\&V consumption or maintained a greater 228 F\&V consumption got the lowest cost, but no statistically significant results were found after 229 adjusting for several background factors.

231 Studies on changes in diet and LTPA and their associations with SA cost has been very limited.

232 Our study showed that not only having healthy lifestyles but also improving them may decrease 233 SA cost for the employer. The associations were clearer and stronger when the employee shifted 234 from semi-healthy to the healthiest group of diet or LTPA, compared to those with slighter 235 improvements. For example, improving from non-daily $\mathrm{F} \& \mathrm{~V}$ consumption to consume $\mathrm{F}$ or $\mathrm{V}$ 236 daily, as well as increasing LTPA level from inactive to moderate, did not get significantly 237 lower cost compared to those with continuously unhealthy lifestyles. Similarly, in a previous 238 study using the same data (Lahti et al., 2012), employees who raised their LTPA level from 239 inactive to vigorous had a significantly lower risk for both shorter and longer SA compared to 240 those remaining inactive, whereas increasing LTPA level from inactive to moderate did not 241 decrease the risk significantly. In our study, being physically active in phase 1 seemed to protect 242 from further SA cost despite of decreases in LTPA. The results may reflect participant's earlier, 243 possibly long-term good fitness status rather than the effect of change, as we do not know 244 participant's LTPA status before phase 1. 
246 Previous studies have shown that being physically active may decrease employee's SA (Kerner 247 et al., 2017) and their cost for the employer (Tolonen et al., 2017) compared to those who are 248 less active, whereas the associations of diet with SA are still unclear (Robroek et al., 2011; 249 Fitzgerald, Kirby, Murphy, \& Geaney, 2016). Our results are in line with these findings. The 250 beneficial effect of PA on SA may be partly explained by the preventive impact of PA on 251 musculoskeletal disorders which are one of the major causes of SA (Haukka et al., 2013; van 252 Amelsvoort, Spigt, Swaen, \& Kant, 2006). PA, especially moderate activity, may also enhance 253 immune function (Romeo, Wärnberg, Pozo, \& Marcos, 2010), which could lead to decreased 254 short-term SA. Short-term SA has been shown to be associated especially with minor and 255 common illnesses such as respiratory disorders, headache and gastroenteritis (Feeney, North, 256 Head, Canner, \& Marmot, 1998). The potential effect of diet on short-term SA may relate to 257 the capacity of F\&V to modify antioxidant pathways and immune system (Lampe, 1999).

259 Although the changes in diet were not independently associated with the cost, the joint 260 associations of healthy diet and PA may produce cost savings for the employer. The joint 261 associations may be partly explained by weight changes as the beneficial effects of diet and PA 262 changes on health are often related to that. For example, the beneficial effects of improvements 263 in diet and PA on blood lipid metabolism (GA Kelley \& Kelley, 2012) and some cancers 264 (Davies et al., 2011) have been perceived to be explained by weight change. Moreover, previous 265 studies have shown that obesity is strongly associated with SA (K Neovius, Johansson, Kark, 266 \& Neovious, 2009). Nevertheless, in addition to weight control, improving diet and PA have 267 several other beneficial effects on individual's health, e.g. through decreased blood pressure 268 and blood glucose, which may further decrease employer's cost (Kowlessar et al., 2011). 


\section{Strengths and Limitations}

The strength of this study is the large data set with identical questions on LTPA and diet in phases 1 and 2 . The response rates in phases $1(67 \%)$ and $2(83 \%)$ were at least satisfactory, and the characteristic differences between responders and non-responders were relatively minor (Lahelma et al., 2013). Thus, the HHS cohort participants represent well the target population, middle-aged municipal employees in Finland (Laaksonen et al., 2008). Participants who were older, in higher occupational classes and with shorter SA tended to be more likely to respond in phase 1. The cohort is not representative of the Finnish general population, e.g. as women's proportion in the cohort is large (Lahelma et al., 2013). Comparison between countries may be challenging because of differences in legislation, different methods of measurements and definitions of short-term SA. However, the average number of short-term SA days an employee takes in Finland is at the average level among EU countries (Parent-Thirion, Macías, Hurley, \& Vermeylen, 2007).

\section{Employer's comprehensive registers on employees' short-term SA and individual annual gross} salaries enabled us to estimate the associations of diet and LTPA with employer's real cost, which are rarely investigated. Data of short-term SA are not often available because of lack of the registers, or the data are derived from employees' self-reporting health questionnaires which may be inaccurate. In addition, we were able to control for several covariates that associate with SA, F\&V consumption and LTPA. The design of our study was prospective, looking first at changes in diet and LTPA in approximately 5-year interval (phase 1-2007) and examining the association of these changes with cost of short-term SA occurring during the next 5-year interval (2008-12). This design gives some suggestion about the direction of the association between F\&V consumption, LTPA and SA. As changes in F\&V consumption and LTPA may 
294 be indicative of participant's health status, we aimed to control this confounding at least 295 partially by adjusting for SA that occurred during one year before the SA follow-up (2008-12).

297 It needs to be acknowledged, however, that the direct salary cost form only a part of the total 298 cost of short-term SA that changes in diet and LTPA may provide to the employer. Unhealthy 299 diet and physical inactivity may increase also other direct and indirect cost for the employer, 300 e.g. through reduced productivity at work, hiring substitutes and medical care cost. Insufficient $301 \quad F \& V$ consumption has been associated with a degree of productivity loss at work (Robroek et 302 al., 2011) and inadequate PA with increased medical care cost and presenteeism (Kowlessar et 303 al., 2011; Walker, Tullar, Diamond, Kohl, \& Amick, 2017). To evaluate the effect of changes 304 in diet and LTPA on the total cost for the employer, all the direct and indirect costs should be 305 estimated.

307 There are several challenges in investigating changes in diet and PA. First, the information of 308 changes in participants' diet and LTPA is based on participants' self-reports only in two 309 different time points and may therefore not represent real change. Secondly, we cannot know 310 when and in which timespan the changes of diet and LTPA have occurred. The effect of change in diet or LTPA may be different, if the employee has changed his/her lifestyle habits gradually over the 5-year follow-up compared to sudden change in the beginning or in the end of the

313 follow-up. In addition, we do not know participants' background before phase 1 concerning 314 diet and LTPA, which may have a remarkable effect on participant's current health and the 315 impact of change. Changes in diet and PA may also yield such longitudinal effects on health 316 and cost, e.g. through weight loss, which appear after a longer timespan than we had in our 317 study. 
319 F\&V consumption and LTPA are derived from self-reports, which potentially results in 320 reporting bias, especially as $\mathrm{F} \& \mathrm{~V}$ consumption and PA are often overestimated. We used 321 frequency of $\mathrm{F} \& \mathrm{~V}$ consumption to indicate the healthiness of diet, which may only partly 322 represent the real healthiness of diet. Firstly, participants with daily F\&V consumption do not 323 necessarily meet the nutrition recommendations, if F\&V portion sizes are small. Participants' 324 diet could be estimated more precisely if we had information on the amount of $\mathrm{F} \& \mathrm{~V}$ consumption in addition to frequency. That could yield also stronger estimates of SA cost for diet. Secondly, the healthiness of diet consists of adequate F\&V consumption together with other healthy dietary choices. On the other hand, in previous studies concerning SA, both F\&V consumption and dietary indices are used to measure the healthiness of employee's diet, and the results vary in both cases (Robroek et al. 2011; Fitzgerald et al., 2016). In addition, self330 report PA questionnaires have demonstrated good reliability while no single type of PA questionnaire has proven superior (Silsbury, Goldsmith, \& Rushton, 2015; van Poppel,

332 Chinapaw, Mokkink, van Mechelen, \& Terwee, 2010).

\section{Conclusions}

335 Improving employees' diet and LTPA may reduce employer's direct cost of SA. We found that employees who improved their F\&V consumption from non-daily to daily and persevered 337 physically active caused significantly lower cost of short-term ( $<10$ working days) SA spells

338 to the employer than those remaining non-daily $\mathrm{F} \& \mathrm{~V}$ consumers and physically inactive 339 through the 5-year follow-up. Furthermore, employees who persisted physically active or 340 improved their activity from moderate to active got one-fifth lower cost for the employer than 341 those remaining inactive. To estimate the total cost savings which improvements in diet and 342 LTPA may produce for the employer, the effect of other direct and indirect cost should also be 343 evaluated. 


\section{Acknowledgements}

346 We thank the City of Helsinki, its personnel administration and all participating employees.

\section{$348 \quad$ Funding}

349 This work was supported by the Finnish Work Environment Fund [grant number \#116178 to

$350 \mathrm{JL}$ ], the Academy of Finland [grant number \#1294566 to JL, and grant number \#1294514 to 351 OR], and the Juho Vainio Foundation [grants to OR and NK].

\section{Declaration of Interest Statement}

354 The authors declare that they have no competing interests.

\section{References}

Candari, C. J., Cylus, J., Nolte, E. (2017). Assessing the economic costs of unhealthy diets and low physical activity: an evidence review and proposed framework (Health policy series, 47). Copenhagen: WHO Regional Office for Europe.

Davies, N. J., Batehup, L., \& Thomas, R. (2011). The role of diet and physical activity in breast, colorectal, and prostate cancer survivorship: a review of the literature. British Journal of Cancer, 105(Suppl. 1), S52-S73.

Edwards, P. \& Greasley, K. (2010). Absence from work [Report available electronic format only]. Dublin: European Foundation for the Improvement of Living and Working Conditions.

Retrieved

from https://www.eurofound.europa.eu/publications/report/2010/absence-from-work

Feeney, A., North, F., Head, J., Canner, R., \& Marmot M. (1998). Socioeconomic and sex differentials in reason for sickness absence from the Whitehall II Study. Occupational \& Environmental Medicine, 55(2), 91-98. 
370

371

372

373

374

375

376

377

378

379

380

381

382

383

384

Fitzgerald, S., Kirby, A., Murphy, A., \& Geaney, F. (2016). Obesity, diet quality and absenteeism in a working population. Public Health Nutrition, 19(18), 3287-3295.

Haukka, E., Kaila-Kangas, L., Ojajärvi, A., Miranda, H., Karppinen, J., Viikari-Juntura, E., ... Leino-Arjas, P. (2013). Pain in multiple sites and sickness absence trajectories: A prospective study among Finns. Pain, 154(2), 306-312.

Hultin, H., Lindholm, C., Malfert, M., \& Möller J. (2012). Short-term sick leave and future risk of sickness absence and unemployment - the impact of health status. BMC Public Health, $12,861$.

Kanerva, N., Pietiläinen, O., Lallukka, T., Rahkonen, O., \& Lahti, J. (2018). Unhealthy lifestyle and sleep problems as risk factors for increased direct employers' cost of short-term sickness absence. Scandinavian Journal of Work, Environmental \& Health, 44(2), 192-201.

Kelley, G. A. \& Kelley, K. S. (2012). Comparison of Aerobic Exercise, Diet or Both on Lipids and Lipoproteins in Adults: A Meta-Analysis of Randomized Controlled Trials. Clinical Nutrition, 31(2), 156-167.

Kerner, I., Rakovac, M., \& Lazinica, B. (2017). Leisure-time physical activity and absenteeism. Archives of Industrial Hygiene and Toxicology, 68(3), 159-170.

Kowlessar, N. M., Goetzel, R. Z., Carls, G. S., Tabrizi, M. J. \& Guindon, A. (2011). The Relationship Between 11 Health Risks and Medical and Productivity Costs for a Large Employer. Journal of Occupational and Environmental Medicine, 53(5), 468-477.

Kujala, U. M., Kaprio, J., Sarna, S., \& Koskenvuo, M. (1998). Relationship of Leisure-Time Physical Activity and Mortality: The Finnish Twin Cohort. JAMA, 279(6), 440-444.

Laaksonen, M., Aittomäki, A., Lallukka, T., Rahkonen, O., Saastamoinen, P., Silventoinen, K., \& Lahelma, E. (2008). Register-based study among employees showed small nonparticipation bias in health surveys and check-ups. Journal of Clinical Epidemiology, 61(9), 900-906.

Lahelma, E., Aittomäki, A., Laaksonen, M., Lallukka, T., Martikainen, P., Piha, K., ... Saastamoinen, P. (2013). Cohort Profile: The Helsinki Health Study. International Journal of Epidemiology, 42(3):722-730. 
Lahti, J., Lahelma, E., \& Rahkonen, O. (2012). Changes in leisure-time physical activity and subsequent sickness absence: A prospective cohort study among middle-aged employees. Preventive Medicine, 55(6), 618-622.

Lampe, J. W. (1999). Health effects of vegetables and fruit: assessing mechanisms of action in human experimental studies. American Journal of Clinical Nutrition, 70(3), 475-490.

Leijten, F. R., van den Heuvel, S. G., Ybema, J. F., van der Beek, A. J., Robroek, S. J., \& Burdorf, A. (2014). The influence of chronic health problems on work ability and productivity at work: a longitudinal study among older employees. Scandinavian Journal of Work, Environmental \& Health, 40(5):473-482.

Neovius, K., Johansson, K., Kark, M., \& Neovius, M. (2009). Obesity status and sick leave: a systematic review. Obesity Reviews, 10(1), 17-27.

Parent-Thirion, A., Macías, E. F., Hurley, J., \& Vermeylen, G. (Ed.). (2007). Fourth European working conditions survey (Research report). Dublin: European Foundation for the Improvement of Living and Working Conditions.

Proper, K. \& van Mechelen, W. (2008). Effectiveness and economic impact of worksite interventions to promote physical activity and healthy diet: Background paper prepared for the WHO/WEF Joint Event on Preventing Noncommunicable Diseases in the Workplace (Dalian/ China, September 2007). Geneva: World Health Organization 2008. Retrieved from World Health Organization website:

\section{http://ww.who.int/dietphysicalactivity/Proper_K.pdf}

Robroek, S. J. W., van den Berg, T. I. J., Plat, J. F., \& Burdorf, A. (2011). The role of obesity and lifestyle behaviours in a productive workforce. Occupational \& Environmental Medicine, 68(2), 134-139.

Romeo, J., Wärnberg, J., Pozo, T., \& Marcos, A. (2010). Physical activity, immunity and infection. Proceedings of the Nutrition Society, 69(03), 390-399.

Silsbury, Z., Goldsmith, R., \& Rushton, A. (2015). Systematic review of the measurement properties of self-report physical activity questionnaires in healthy adult populations. $B M J$ Open, 5(9). 
426

427

428

429

430

431

432

434

435

436

437

438

439

440

441

442

443

444

445

446

447

Statistics Finland (2018, October 15). Official Statistics of Finland: Index of wage and salary earnings 2018, $3^{\text {rd }}$ quarter [Web publication]. Retrieved from: https://www.stat.fi/til/ati/2018/03/index_en.html

The National Nutrition Council of Finland. (2014). Terveyttä ruoasta - Suomalaiset ravitsemussuositukset 2014 ( $2^{\text {nd }}$ ed.). Tampere: Juvenes Print - Suomen Yliopistopaino Oy.

Tolonen, A., Rahkonen, O., \& Lahti, J. (2017). Leisure-time physical activity and direct cost of short-term sickness absence among Finnish municipal employees. Archives of Environmental \& Occupational Health, 72(2), 93-98.

Van Amelsvoort, L. G. P. M., Spigt, M. G., Swaen, G. M. H., \& Kant, I. (2006). Leisure time physical activity and sickness absenteeism; a prospective study. Occupational Medicine, 56(3), 210-212.

Van den Berg, S., Burdorf, A., \& Robroek, S. J. W. (2017). Associations between common diseases and work ability and sick leave among health care workers. International Archives of Occupational and Environmental Health, 90(7), 685-693.

Van Poppel, M. N. M., Chinapaw, M. J. M., Mokkink, L. B., van Mechelen, W., \& Terwee, C. B. (2010). Physical Activity Questionnaires for Adults. Sports Medicine, 40(7):565-600.

Walker, K. Z., O’Dea, K., Gomez, M., Girgis, S., \& Colagiuri, R. Diet and exercise in the prevention of diabetes. Journal of Human Nutrition and Dietetics, 23(4), 344-352.

Walker, T. J., Tullar, J. M., Diamond, P. M., Kohl, H. W., \& Amick, B. C. (2017). The Association of Self-Reported Aerobic Physical Activity, Muscle Strengthening Physical Activity, and Stretching Behavior with Presenteeism. Journal of Occupational and Environmental Medicine, 59(5), 474-479. 


\section{Appendices}

449 Table 1. Short-term sickness absence and their direct cost $(€)$ of short-term sickness absence

450 for the employer over the 5-year follow-up by participants' background characteristics.

\begin{tabular}{|c|c|c|c|c|c|c|}
\hline & \multicolumn{3}{|c|}{ All participants $(n=4157)$} & \multicolumn{3}{|c|}{ Those who have short-term SA $(n=3510)$} \\
\hline & $\begin{array}{l}\text { Mean (SD) } \\
\text { or } n(\%)\end{array}$ & $\begin{array}{l}\text { SA days } \\
(\text { mean, } \text { SD) }\end{array}$ & $\begin{array}{l}\text { SA cost } \\
(\text { mean, } S D)\end{array}$ & $\begin{array}{l}\text { Mean (SD) } \\
\text { or } n(\%)\end{array}$ & $\begin{array}{l}\text { SA days } \\
(\text { mean, } \mathbf{S D})\end{array}$ & $\begin{array}{l}\text { SA cost } \\
(\text { mean, } S D)\end{array}$ \\
\hline Age (mean, SD) & $53.9(5.7)$ & & & $53.3(5.4)$ & & \\
\hline \multicolumn{7}{|l|}{ Gender $(n, \%)$} \\
\hline Women & $3477(83.6)$ & $28(0.6)$ & $3645(73)$ & $3009(85.7)$ & $32(0.6)$ & $4210(79)$ \\
\hline Men & $680(16.4)$ & $17(0.9)$ & $2757(138)$ & $501(14.3)$ & $23(1.1)$ & $3762(167)$ \\
\hline \multicolumn{7}{|c|}{ Occupational position $(n, \%)$} \\
\hline Professionals/managers & $1300(31.3)$ & $16(0.6)$ & $3051(118)$ & $984(28.0)$ & $21(0.8)$ & $4030(142)$ \\
\hline Semi-professionals & $876(21.1)$ & $24(0.9)$ & $3501(135)$ & $761(21.7)$ & $28(1.0)$ & 4037 (146) \\
\hline Routine non-manuals & $1470(35.4)$ & $33(1.0)$ & $3886(112)$ & $1322(37.7)$ & $37(1.0)$ & $4320(118)$ \\
\hline Manual workers & $511(12.3)$ & $33(1.7)$ & $3538(176)$ & $443(12.6)$ & $38(1.8)$ & 4076 (189) \\
\hline \multicolumn{7}{|l|}{ Marital status $(n, \%)$} \\
\hline In relationship & $2917(70.2)$ & $24(0.6)$ & $3344(75)$ & $2452(70.2)$ & $29(0.6)$ & $3982(84)$ \\
\hline Not in relationship & $1221(29.4)$ & $30(1.0)$ & $3869(127)$ & $1042(29.8)$ & $35(1.1)$ & 4530 (138) \\
\hline \multicolumn{7}{|l|}{ Smoking $(n, \%)$} \\
\hline Non-smoker & $3189(76.7)$ & $23(0.5)$ & $3219(70)$ & $2643(75.8)$ & $28(0.6)$ & $3883(78)$ \\
\hline Current smoker & $942(22.7)$ & $36(1.3)$ & $4453(158)$ & $843(24.2)$ & $40(1.4)$ & 4977 (167) \\
\hline \multicolumn{7}{|l|}{ Alcohol use $(n, \%)$} \\
\hline No binge drinking & $1751(42.1)$ & $23(0.7)$ & $3120(92)$ & $1449(41.3)$ & $28(0.8)$ & $3776(103)$ \\
\hline Binge drinking & $2406(57.9)$ & $28(0.7)$ & $3777(90)$ & $2061(58.7)$ & $33(0.8)$ & $4408(98)$ \\
\hline \multicolumn{7}{|l|}{ Sleeping hours $(n, \%)$} \\
\hline $7-8 h$ & $3045(73.2)$ & $26(0.6)$ & $3483(73)$ & $2598(75.3)$ & $30(0.6)$ & $4084(80)$ \\
\hline$<7 \mathrm{~h}$ or $>8 \mathrm{~h}$ & $1045(25.1)$ & $27(1.1)$ & $3546(140)$ & $854(24.7)$ & $33(1.2)$ & 4335 (159) \\
\hline \multicolumn{7}{|c|}{ Occupational physical work load $(n, \%)$} \\
\hline Light & $2741(65.9)$ & $22(0.5)$ & $3282(77)$ & $2272(65.2)$ & $27(0.6)$ & $3959(87)$ \\
\hline Heavy & $1384(33.3)$ & $33(1.0)$ & $3931(118)$ & $1212(34.8)$ & $38(1.1)$ & 4498 (127) \\
\hline
\end{tabular}


452 Table 2. Short-term sickness absence and their direct cost (€) of short-term sickness absence

453 over the 5-year follow-up by changes in diet and physical activity.

\begin{tabular}{|c|c|c|c|c|c|c|}
\hline & \multicolumn{3}{|c|}{ All participants $(n=4157)$} & \multicolumn{3}{|c|}{ Those who have short-term SA $(n=3510)$} \\
\hline & $N(\%)$ & $\begin{array}{l}\text { SA days } \\
(\text { mean, } \text { SD) }\end{array}$ & $\begin{array}{l}\text { SA cost } \\
(\text { mean, } S D)\end{array}$ & $N(\%)$ & $\begin{array}{l}\text { SA days } \\
(\text { mean, } S D)\end{array}$ & $\begin{array}{l}\text { SA cost } \\
(\text { mean, } \text { SD) }\end{array}$ \\
\hline \multicolumn{7}{|c|}{ Change in $\mathrm{F} \& \mathrm{~V}$ consumption } \\
\hline $\begin{array}{r}\text { Continuously } \\
\text { neither daily }\end{array}$ & $445(10.7)$ & $30(2.0)$ & $3983(229)$ & $382(10.9)$ & $35(2.1)$ & $4640(252)$ \\
\hline $\begin{array}{r}\text { Neither daily to } \\
\text { other daily }\end{array}$ & $306(7.4)$ & $28(2.1)$ & $3800(261)$ & $261(7.4)$ & $33(2.4)$ & 4455 (287) \\
\hline $\begin{array}{r}\text { Neither daily to } \\
\text { both daily }\end{array}$ & $203(4.9)$ & $28(2.1)$ & $3442(241)$ & $174(5.0)$ & $33(2.3)$ & 4016 (256) \\
\hline $\begin{array}{r}\text { Other daily to } \\
\text { neither daily }\end{array}$ & $265(6.4)$ & $30(2.0)$ & $3926(257)$ & $227(6.5)$ & $35(2.2)$ & $4583(227)$ \\
\hline $\begin{array}{r}\text { Continuously other } \\
\text { daily }\end{array}$ & $511(12.3)$ & $27(1.4)$ & $3668(203)$ & $420(12.0)$ & $33(1.6)$ & 4462 (229) \\
\hline $\begin{array}{r}\text { Other daily to both } \\
\text { daily }\end{array}$ & $492(11.8)$ & $23(1.3)$ & $3235(181)$ & $421(12.0)$ & $27(1.5)$ & $3780(199)$ \\
\hline $\begin{array}{l}\text { Both daily to } \\
\text { neither daily }\end{array}$ & $130(3.1)$ & $26(2.3)$ & $3599(325)$ & $110(3.1)$ & $31(1.5)$ & $4253(350)$ \\
\hline $\begin{array}{r}\text { Both daily to other } \\
\text { daily }\end{array}$ & $378(9.1)$ & $23(1.5)$ & 3235 (214) & $308(8.8)$ & $28(1.6)$ & 3970 (244) \\
\hline $\begin{array}{r}\text { Continuously both } \\
\text { daily }\end{array}$ & $1427(34.3)$ & $25(0.8)$ & $3290(98)$ & $1207(34.4)$ & $29(0.8)$ & 3890 (107) \\
\hline \multicolumn{7}{|l|}{ Change in LTPA } \\
\hline $\begin{array}{r}\text { Continuously } \\
\text { inactive } \\
\end{array}$ & $418(10.1)$ & $28(1.7)$ & $3723(238)$ & $346(9.9)$ & $34(1.9)$ & 4497 (269) \\
\hline $\begin{array}{r}\text { Inactive to } \\
\text { moderately active }\end{array}$ & $362(8.7)$ & $28(1.9)$ & 3669 (226) & $304(8.7)$ & $34(2.1)$ & $4369(250)$ \\
\hline Inactive to active & $173(4.2)$ & $25(2.5)$ & 3815 (329) & $149(4.2)$ & $30(2.7)$ & 4429 (357) \\
\hline $\begin{array}{r}\text { Moderately active } \\
\text { to inactive }\end{array}$ & $336(8.1)$ & $31(2.1)$ & 3877 (246) & $288(8.2)$ & $36(2.3)$ & $4523(268)$ \\
\hline $\begin{array}{r}\text { Continuously } \\
\text { moderately active }\end{array}$ & 993 (23.9) & $27(1.0)$ & 3485 (127) & $850(24.2)$ & $32(1.1)$ & 4071 (138) \\
\hline $\begin{array}{r}\text { Moderately active } \\
\text { to active }\end{array}$ & $389(9.4)$ & $23(1.3)$ & 3177 (175) & $331(9.4)$ & $27(1.4)$ & 3734 (190) \\
\hline Active to inactive & $169(4.1)$ & $25(2.1)$ & $3520(301)$ & $145(4.1)$ & $30(2.3)$ & $4103(326)$ \\
\hline $\begin{array}{r}\text { Active to } \\
\text { moderately active }\end{array}$ & $395(9.5)$ & $26(1.6)$ & $3608(211)$ & $335(9.5)$ & $31(1.7)$ & 4254 (232) \\
\hline Continuously active & $922(22.2)$ & $22(0.9)$ & 3213 (128) & $762(21.7)$ & $26(1.0)$ & 3887 (144) \\
\hline
\end{tabular}


456 Table 3. Cost estimates ${ }^{\mathrm{a}}$ of changing patterns compared to continuously unhealthy diet and inactive lifestyle.

\begin{tabular}{|c|c|c|c|c|c|c|c|c|}
\hline & \multicolumn{4}{|c|}{ Model $1^{b}$} & \multicolumn{4}{|c|}{ Model $2^{c}$} \\
\hline & $\mathrm{dy} / \mathrm{dx}^{\mathrm{d}}$ & $p$ & \multicolumn{2}{|c|}{$95 \% \mathrm{CI}$} & $d y / d x^{d}$ & $p$ & \multicolumn{2}{|c|}{$95 \% \mathrm{CI}$} \\
\hline \multicolumn{9}{|c|}{ Change in $\mathrm{F} \& \mathrm{~V}$ consumption } \\
\hline $\begin{array}{r}\text { Neither daily to } \\
\text { other daily }\end{array}$ & -247 & 0.393 & -813 & 319 & -59 & 0.818 & -562 & 444 \\
\hline $\begin{array}{r}\text { Neither daily to } \\
\text { both daily }\end{array}$ & -740 & 0.015 & -1335 & -145 & -305 & 0.286 & -866 & 256 \\
\hline $\begin{array}{r}\text { Other daily to } \\
\text { neither daily }\end{array}$ & -250 & 0.409 & -844 & 344 & -18 & 0.948 & -552 & 516 \\
\hline $\begin{array}{r}\text { Continuously } \\
\text { other daily }\end{array}$ & -521 & 0.037 & -1012 & -30 & -199 & 0.374 & -637 & 239 \\
\hline $\begin{array}{l}\text { Other daily to } \\
\text { both daily }\end{array}$ & -805 & 0.001 & -1278 & -331 & -235 & 0.297 & -678 & 207 \\
\hline $\begin{array}{l}\text { Both daily to } \\
\text { neither daily }\end{array}$ & -183 & 0.638 & -946 & 579 & 234 & 0.522 & -482 & 951 \\
\hline $\begin{array}{r}\text { Both daily to } \\
\text { other daily }\end{array}$ & -589 & 0.026 & -1108 & -71 & -256 & 0.285 & -726 & 213 \\
\hline $\begin{array}{r}\text { Continuously } \\
\text { both daily }\end{array}$ & -675 & 0.002 & -1097 & -254 & -194 & 0.318 & -576 & 187 \\
\hline \multicolumn{9}{|l|}{ Change in LTPA } \\
\hline $\begin{array}{r}\text { Inactive to } \\
\text { moderately active }\end{array}$ & -117 & 0.674 & -665 & 431 & 52 & 0.843 & -466 & 571 \\
\hline Inactive to active & -414 & 0.214 & -1066 & 239 & -46 & 0.887 & -682 & 589 \\
\hline $\begin{array}{r}\text { Moderately } \\
\text { active to inactive }\end{array}$ & 39 & 0.893 & -530 & 608 & -14 & 0.959 & -535 & 508 \\
\hline $\begin{array}{r}\text { Continuously } \\
\text { moderately active }\end{array}$ & -301 & 0.182 & -742 & 141 & -276 & 0.183 & -682 & 130 \\
\hline $\begin{array}{r}\text { Moderately } \\
\text { active to active }\end{array}$ & -857 & 0.001 & -1345 & -369 & -542 & 0.022 & -1005 & -78 \\
\hline Active to inactive & -431 & 0.191 & -1076 & 214 & -294 & 0.340 & -897 & 310 \\
\hline $\begin{array}{r}\text { Active to } \\
\text { moderately active }\end{array}$ & -374 & 0.159 & -895 & 146 & -295 & 0.228 & -773 & 185 \\
\hline $\begin{array}{r}\text { Continuously } \\
\text { active }\end{array}$ & -898 & $<0.001$ & -1331 & -464 & -546 & 0.009 & -954 & -137 \\
\hline
\end{tabular}

458 Abbreviations: CI; confidence interval, F\&V; fruit and vegetable, LTPA; leisure-time physical activity.

459 a Employer's direct cost of short-term SA over the 5-year follow-up.

$460 \quad$ b Adjusted for gender, age and work years. The two-part model was used for the analysis. Associations of changes

461 in F\&V consumption and SA cost and associations of changes in LTPA with SA cost were examined separately.

$462{ }^{\mathrm{c}}$ Model $1+$ SA days during the year before 5-year follow-up period, occupational position, marital status, smoking,

463 binge drinking, sleeping hours and occupational physical work load.

$464{ }^{\mathrm{d}}$ Marginal effects at covariate means are derived from the two-part model which consists of generalized linear model with binomial regression, and generalized linear model with gamma distribution and log-link function. 
Estimates in euros of consistently healthier or changing patterns over the follow-up compared to continuously unhealthy diet and inactive lifestyle.

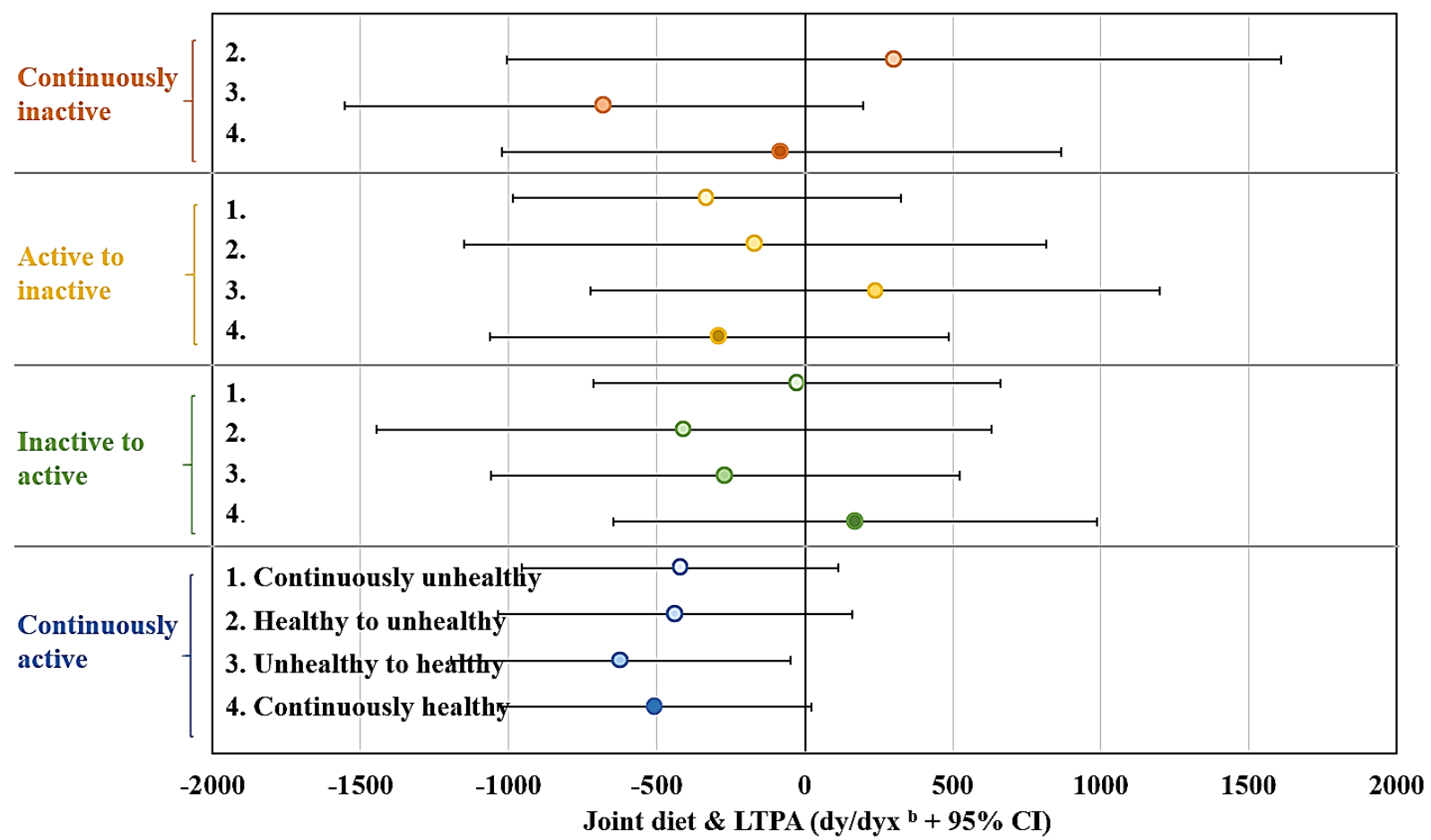

471 Figure 1. Joint associations of changes in $\operatorname{diet}^{\mathrm{a}}$ and leisure-time physical activity with 472 employer's direct cost $(€)$ of short-term sickness absence over the 5-year follow-up.

474 Abbreviations: F\&V; fruit and vegetable, LTPA; leisure-time physical activity, SA; sickness absence.

${ }^{\mathrm{a}} \mathrm{F} \& \mathrm{~V}$ consumption is used as an indicator of healthiness of participant's diet, where non-daily $\mathrm{F} \& \mathrm{~V}$ consumption 477 represents unhealthy diet and daily F\&V consumption healthy diet.

$478{ }^{\mathrm{b}}$ Marginal effects in euros in different joint groups compared to those with continuously unhealthy diet and 479 physical inactivity. Vertical line at zero represents the reference group. Joint variable adjusted for gender, age and work years, SA days during the year before 5-year follow-up period, occupational position, marital status,

481 smoking, binge drinking, sleeping hours and occupational physical work load. The two-part model was used for 482 the analysis. 